\title{
A Comparison of Carbon Dioxide Elimination Measurements Between a Portable Indirect Calorimeter and Volumetric Capnography Monitor: An In Vitro Simulation
}

\author{
Craig D Smallwood RRT, Enid E Martinez MD, and Nilesh M Mehta MD
}

\begin{abstract}
BACKGROUND: Gas exchange measurements for carbon dioxide elimination $\left(\dot{\mathrm{V}}_{\mathrm{CO}_{2}}\right)$ and oxygen consumption $\left(\dot{\mathrm{V}}_{\mathrm{O}_{2}}\right)$ have been used to derive resting energy expenditure and guide energy prescription. Volumetric capnography is used in intensive care units and provides $\dot{\mathrm{V}}_{\mathrm{CO}_{2}}$ measurements that could be used for titrating respiratory and nutritional support. We have recently suggested that measuring $\dot{\mathrm{V}}_{\mathrm{CO}_{2}}$ may be sufficient to obtain a reasonable estimate of energy expenditure. However, data describing the accuracy of gas exchange measurement devices are limited. METHODS: We used an in vitro simulation model to test the accuracy of gas exchange measurements by 2 devices: the CCM Express indirect calorimeter and the NM3, a volumetric capnography monitor. A Huszczuk gas injection system combined with a high-fidelity lung simulator was used to simulate $\dot{\mathrm{V}}_{\mathrm{O}_{2}}$ and $\dot{\mathrm{V}}_{\mathrm{CO}_{2}}$ values in the pediatric and adult range. Bland-Altman analysis was used to examine the agreement between the measured and simulated values across a range of tidal volumes and gas exchange values. Additionally, agreement between the 2 devices was examined. RESULTS: During the adult simulation with the CCM Express, the mean bias (95\% CI) for $\dot{\mathrm{V}}_{\mathrm{CO}_{2}}$ values was $-\mathbf{1 2 . 6 \%}$ $(-16.4$ to $-8.8 \%)$ and $-17.5 \%(-19.9$ to $-15.1 \%)$ for $\dot{V}_{O_{2}}$ values. For the pediatric simulation with the CCM Express, mean bias for $\dot{\mathrm{V}}_{\mathrm{O}_{2}}$ was $-14.7 \%(-16.4$ to $-13.0 \%)$ and $\dot{\mathrm{V}}_{\mathrm{CO}_{2}}$ was $-10.9 \%$ $(-13.5$ to $-8.3 \%)$. For the adult and pediatric simulations with the NM3, the bias for $\dot{\mathrm{V}}_{\mathrm{CO}_{2}}$ was $-8.2 \%(-15.7$ to $-0.7 \%)$ and $-8.3 \%(-19.4$ to $-2.8 \%)$, respectively. Between the 2 devices, the mean bias was $-4.4 \%(-10.2$ to $1.3 \%)$ and $-2.3 \%(-11.4$ to $6.8 \%)$ for the adult and pediatric $\dot{\mathrm{V}}_{\mathrm{CO}_{2}}$ simulations, respectively. CONCLUSIONS: Currently available portable gas exchange monitors demonstrated acceptable agreement with reference $\dot{\mathbf{V}}_{\mathrm{O}_{2}}$ and $\dot{\mathrm{V}}_{\mathrm{CO}_{2}}$ values in an in vitro simulation. The devices demonstrated good agreement with each other. Key words: carbon dioxide elimination; oxygen consumption; mechanical ventilation; volumetric capnography. [Respir Care 2016;61(3):354-358. (C) 2016 Daedalus Enterprises]
\end{abstract}

\section{Introduction}

Accurate measurements of oxygen consumption $\left(\dot{\mathrm{V}}_{\mathrm{O}_{2}}\right)$ and/or carbon dioxide elimination $\left(\dot{\mathrm{V}}_{\mathrm{CO}_{2}}\right)$ may facilitate the prescription of optimal nutrition, titration of mechanical ventilation, and assessment of substrate oxidation in pediatric and adult subjects during critical illness. ${ }^{1-4}$ Indi-

\footnotetext{
The authors are affiliated with the Division of Critical Care Medicine, Department of Anesthesiology, Perioperative and Pain Medicine, Boston Children's Hospital, and Harvard Medical School, Boston, Massachusetts. Dr Mehta is also affiliated with the Center for Nutrition, Boston Children's Hospital, Boston, Massachusetts.
}

Mr Smallwood has disclosed a relationship with Hill-Rom Medical. rect calorimeters and gas exchange monitors are now being used in out-patient clinics, in-patient settings, and even home environments. ${ }^{5-7}$ Although a number of portable gas exchange monitoring devices are now commercially available, there is a paucity of data on validation of individual devices and on agreement between such devices. Therefore, we sought to examine the accuracy of an indirect

\footnotetext{
Correspondence: Craig D Smallwood RRT, Division of Critical Care Medicine, Department of Anesthesiology, Pain, and Perioperative Medicine, MSICU Office, Bader 634, Boston Children's Hospital, 300 Longwood Avenue, Boston, MA 02115. E-mail: craig.smallwood@childrens.harvard.edu.
}

DOI: $10.4187 /$ respcare.04282 
calorimeter and a volumetric capnography device using a gas exchange simulator across a range of pediatric and adult respiratory values.

\section{Methods}

A laboratory simulation model was constructed that allowed precise control of respiratory mechanics and gas exchange parameters; the model incorporated a high-fidelity lung simulator and a mass flow controller. Gas exchange simulation was based upon gas dilution and permitted the control of different levels of $\dot{\mathrm{V}}_{\mathrm{CO}_{2}}$ and $\dot{\mathrm{V}}_{\mathrm{O}_{2}} \cdot{ }^{8} \mathrm{We}$ aimed to simulate gas exchange values for 2 discrete subject sizes along with an array of appropriate respiratory mechanics that correspond to values observed in an ICU.

\section{Gas Exchange Monitors}

We tested 2 portable (table top) gas exchange monitors: an indirect calorimeter, the CCM Express (MGC Diagnostics, Saint Paul, Minnesota), and a volumetric capnography monitor, the NM3 (Philips Healthcare, Eindhoven, Netherlands), which measures $\dot{\mathrm{V}}_{\mathrm{CO}_{2}}$. Each device was calibrated according to the manufacturer's specifications before testing, and appropriate airway adapters were used. All volumes were corrected to testing conditions (ambient temperature and pressure).

\section{Lung Mechanics Simulation}

The ASL 5000 breathing simulator (Ingmar Medical, Pittsburg, Pennsylvania) was used to control tidal volumes, inspiratory times, breathing frequencies, and compliance. For the pediatric simulation (a $35-\mathrm{kg}$ subject) the pulmonary compliance was set at $35 \mathrm{~mL} / \mathrm{cm} \mathrm{H}_{2} \mathrm{O}$ with breathing frequency of 25 breaths/min, inspiratory time of $0.9 \mathrm{~s}$, and tidal volumes $\left(\mathrm{V}_{\mathrm{T}}\right)$ set to 175,245 , and $315 \mathrm{~mL}$, corresponding to 5,7 , and $9 \mathrm{~mL} / \mathrm{kg}$, respectively. For the adult simulation (a 70-kg subject) the pulmonary compliance was set at $70 \mathrm{~mL} / \mathrm{cm} \mathrm{H}_{2} \mathrm{O}$, with breathing frequency of 20 breaths/min, inspiratory time of $1.1 \mathrm{~s}$, and $\mathrm{V}_{\mathrm{T}}$ set to 350,490 , and $630 \mathrm{~mL}$, corresponding to 5,7 , and $9 \mathrm{~mL} / \mathrm{kg}$, respectively. The accuracy of volume delivery with the ASL 5000 is $\pm 2 \%$.

\section{Gas Exchange Simulation}

The gas injection model used to simulate $\dot{\mathrm{V}}_{\mathrm{O}_{2}}$ and $\dot{\mathrm{V}}_{\mathrm{CO}_{2}}$ has been described previously. ${ }^{8}$ A schematic of the experimental setup is shown in Figure 1. A mass flow controller (FMA-2605A, Omega Engineering, Stamford, Connecticut) was utilized to control the injection of a specialized test gas composed of $21 \% \mathrm{CO}_{2}$, with the balance nitrogen. Accuracy of the mass flow controller is $\pm 0.8 \%$ of the

\section{QUICK LOOK}

\section{Current knowledge}

Carbon dioxide elimination $\left(\dot{\mathrm{V}}_{\mathrm{CO}_{2}}\right)$ and oxygen consumption $\left(\dot{\mathrm{V}}_{\mathrm{O}_{2}}\right)$ are used to calculate resting energy expenditure and guide energy prescription. We recently proposed that measuring $\dot{\mathrm{V}}_{\mathrm{CO}_{2}}$ alone may be sufficient to approximate energy expenditure measured by indirect calorimetry. However, data describing the accuracy of portable devices to measure gas exchange are limited.

\section{What this paper contributes to our knowledge}

The currently available portable gas exchange monitors tested in the present investigation were in reasonable agreement with reference $\dot{\mathrm{V}}_{\mathrm{O}_{2}}$ and $\dot{\mathrm{V}}_{\mathrm{CO}_{2}}$ values in an in vitro simulation. Agreement between the devices was good.

measurement reading. A customized baffle and reservoir assembly was constructed in accordance with previous methods in order to appropriately integrate the test gas into the breathing simulator. Test gas accumulates in the reservoir during exhalation. During the inspiratory cycle, oneway valves directed test gas from the reservoir, which mixes with inspired ambient air and is mixed inside the lung simulator. Upon exhalation, one-way valves direct the mixed gas away from the reservoir to prevent any more mixing and out past the airway adapter. For $\dot{\mathrm{V}}_{\mathrm{CO}_{2}}$ simulation, the volume of $\mathrm{CO}_{2}$ injected can be calculated by multiplying the $\mathrm{CO}_{2}$ fraction of the test gas by the flow $(0.21 \times$ test gas flow $)$. For $\dot{\mathrm{V}}_{\mathrm{O}_{2}}$, the inspired gas is diluted by a known amount of $\mathrm{N}_{2}$ and $\mathrm{CO}_{2}$. The relationship between $\mathrm{F}_{\mathrm{IO}_{2}}$, inspired gas volume, and total gas volume is shown in Equation 1. Of note, this relationship can be simplified for a test gas with the $\mathrm{CO}_{2}$ content equal to the ambient $\mathrm{F}_{\mathrm{IO}_{2}}\left(\dot{\mathrm{V}}_{\mathrm{O}_{2}}=0.21 \times\right.$ test gas flow $)$. For both the pediatric and adult simulations, the system was set to mimic values at a level typically observed and also $20 \%$ above and $20 \%$ below this level..$^{9,10}$ For the pediatric model, $\dot{\mathrm{V}}_{\mathrm{O}_{2}}$ and $\dot{\mathrm{V}}_{\mathrm{CO}_{2}}$ were simulated at 112,140 , and $168 \mathrm{~mL} / \mathrm{min}$; corresponding to $3.2,4$, and $4.8 \mathrm{~mL} / \mathrm{kg} / \mathrm{min} .{ }^{11}$ For the adult model, $\dot{\mathrm{V}}_{\mathrm{O}_{2}}$ and $\dot{\mathrm{V}}_{\mathrm{CO}_{2}}$ were simulated at 168, 210, and $252 \mathrm{~mL} / \mathrm{min}$, corresponding to $3.2,4$, and 4.8 $\mathrm{mL} / \mathrm{kg} / \mathrm{min}$,

$$
\dot{V}_{O_{2}}=\left[F_{I O_{2}}-\left(\frac{F_{102} \times \dot{V}_{i}}{\dot{V}_{\text {total }}}\right)\right] \times \dot{V}_{\text {total }}
$$

where $\dot{V}_{\mathrm{i}}$ is the inspired volume per unit time of ambient air, and $\dot{\mathrm{V}}_{\text {total }}$ is the sum of $\dot{\mathrm{V}}_{\mathrm{i}}$ and the total test gas flow. 


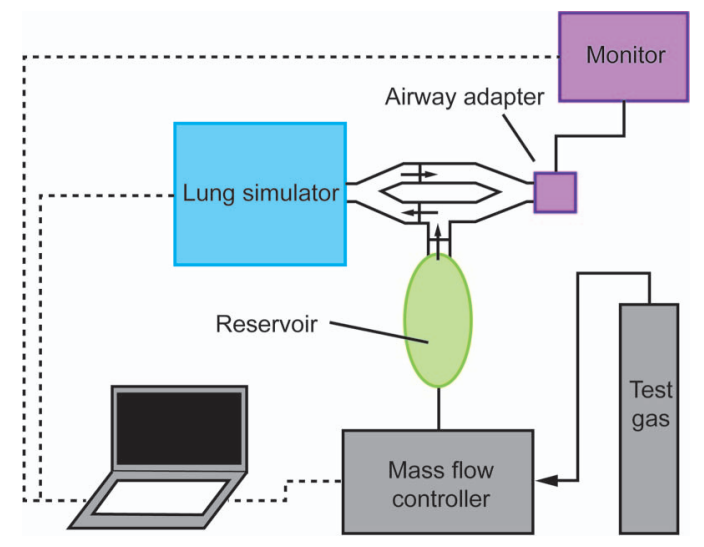

Fig. 1. Schematic of the experimental setup. The small arrows represent the direction of gas flow through a one-way valve. Test gas accumulates in the reservoir during exhalation. During the inspiratory cycle, one-way valves direct test gas from the reservoir, which mixes with inspired ambient air and is mixed inside the lung simulator. Upon exhalation, one-way valves direct the mixed gas away from the reservoir to prevent any more mixing and out past the airway adapter of the gas exchange monitor.

The overall aim was to subject the devices to testing levels across the range of expected $\mathrm{V}_{\mathrm{Ts}}$, gas exchange, and other parameters typically observed in critically ill pediatric and adult subjects. Each device was tested across 9 distinct combinations of $\mathrm{V}_{\mathrm{Ts}}$ and gas exchange values for the pediatric model and 9 combinations for the adult model.

\section{Statistical Analysis}

Bland-Altman analysis was used to quantify the accuracy of the devices by comparison of gas exchange measurements for each device and the set values on the simulator. ${ }^{12}$ Mean bias and $95 \%$ CIs were computed. Further, the agreement of $\dot{\mathrm{V}}_{\mathrm{CO}_{2}}$ measurements between the devices was done using Bland-Altman analysis. For the purpose of this experiment, we decided a priori that limits of agreement within $\pm 20 \%$ would be deemed clinically acceptable. ${ }^{13}$ Analyses were conducted using Prism 5.04 (GraphPad Software, La Jolla, California).

\section{Results}

A total of 18 unique combinations of gas exchange values and $\mathrm{V}_{\mathrm{T}}$ levels were tested, each of which was recorded for a 5-min period. For the adult simulation of $\dot{\mathrm{V}}_{\mathrm{CO}_{2}}$, the mean biases (95\% CIs) for the CCM Express and NM3 compared with the simulated reference values are shown in Table 1 and depicted in Figure 2, A and B. The mean bias $(95 \% \mathrm{CI})$ for adult $\dot{\mathrm{V}}_{\mathrm{CO}_{2}}$ readings between the 2 devices was $-4.4 \%$ ( -10.2 to $1.3 \%$ ) (Fig. $2 \mathrm{C}$ ).

For the pediatric simulation of $\dot{\mathrm{V}}_{\mathrm{CO}_{2}}$, the mean biases (95\% CI) for $\dot{\mathrm{V}}_{\mathrm{CO}_{2}}$ values for the devices are shown in
Table 1. Results From the Experiment

\begin{tabular}{lllcl}
\hline \hline Parameter & Range & \multicolumn{1}{c}{ Device } & Mean Bias (\%) & 95\% CI (\%) \\
\hline$\dot{\mathrm{V}}_{\mathrm{CO}_{2}}$ & Adult & $\mathrm{CCM}$ Express & -12.6 & -16.4 to -8.8 \\
& Adult & $\mathrm{NM} 3$ & -8.2 & -15.7 to -0.7 \\
& Pediatric & $\mathrm{CCM}$ Express & -10.9 & -13.5 to -8.3 \\
$\dot{\mathrm{V}}_{\mathrm{O}_{2}}$ & Pediatric & $\mathrm{NM} 3$ & -8.3 & -19.4 to 2.8 \\
& Adult & $\mathrm{CCM}$ Express & -17.5 & -19.9 to -15.1 \\
& Pediatric & $\mathrm{CCM}$ Express & -14.7 & -16.4 to -13.0 \\
$\begin{array}{l}\text { Mean bias was calculated as } 100 \times \text { (measured value } \\
\text { value)/2]. }\end{array}$ & \\
\hline
\end{tabular}

Table 1 and depicted in Figure 3, A and B. The mean (95\% CI) bias for pediatric $\dot{\mathrm{V}}_{\mathrm{CO}_{2}}$ readings between the 2 devices was $-2.3 \%$ ( -11.4 to $6.8 \%$ ) (Fig. 3C).

For the measurement of $\dot{\mathrm{V}}_{\mathrm{O}_{2}}$ using the CCM Express, mean bias $(95 \% \mathrm{CI})$ for the adult and pediatric range are shown in Table 1 and depicted in Figure 4, A and B.

\section{Discussion}

We have reported the results of an in vitro experiment, testing 2 commonly used gas exchange measurement devices. Our study design allowed testing across a wide range of simulated pediatric and adult ranges for respiratory and metabolic values. Our results suggest that the indirect calorimeter and volumetric capnography devices were able to measure gas exchange values on average within $5 \%$ of each other, with mean bias and $95 \%$ CIs that were within the a priori defined clinically acceptable range compared with the reference method. The CCM Express demonstrated $\dot{\mathrm{V}}_{\mathrm{O}_{2}}$ measurements that were within the limits of agreement. Furthermore, there was reasonable agreement between the 2 devices for $\dot{\mathrm{V}}_{\mathrm{CO}_{2}}$ measurements. Our results support the use of portable gas exchange devices in adult and pediatric applications. However, their validation in the clinical setting must be further explored.

The Weir equation, which utilizes both $\dot{\mathrm{V}}_{\mathrm{O}_{2}}$ and $\dot{\mathrm{V}}_{\mathrm{CO}_{2}}$ to calculate energy expenditure, requires an indirect calorimeter. Recently, we have introduced an equation for estimation of energy expenditure that relies only on $\dot{\mathrm{V}}_{\mathrm{CO}_{2}}$ measurements and may be used in the absence of an indirect calorimeter. ${ }^{14}$ Bedside $\dot{\mathrm{V}}_{\mathrm{CO}_{2}}$ measurement devices are also used to titrate settings and assess changes in respiratory physiology in the ICUs. However, since devices to measure $\dot{\mathrm{V}}_{\mathrm{CO}_{2}}$ (such as the NM3) have not been compared head to head with an indirect calorimeter, it is necessary to demonstrate their accuracy and agreement.

We have previously reported a similar simulation model to test the accuracy of a gas exchange device to 

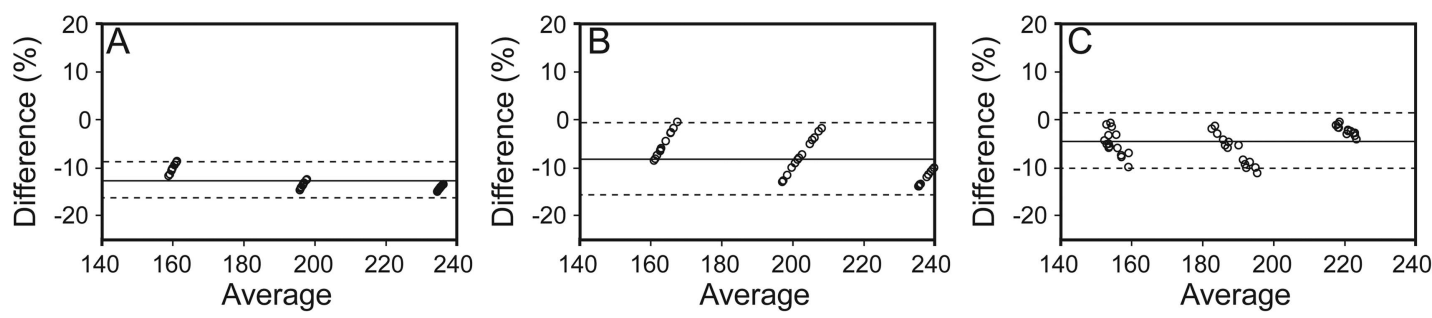

Fig. 2. Bland-Altman plots of carbon dioxide elimination $\left(\dot{\mathrm{CO}}_{2}\right)$ results in the adult range compared with the simulated values and with each other. MGC Diagnostics CCM Express indirect calorimeter $(A)$ and Philips Healthcare NM3 $(B)$, where difference $(\%)=100 \times($ measured value - set value)/[(measured value + set value)/2] versus average of the measured value and set value. C: Comparison of MGC with NM3, where difference $(\%)=100 \times(\mathrm{CCM}-\mathrm{NM} 3) /[(\mathrm{CCM}+\mathrm{NM}) / 2]$ versus average.
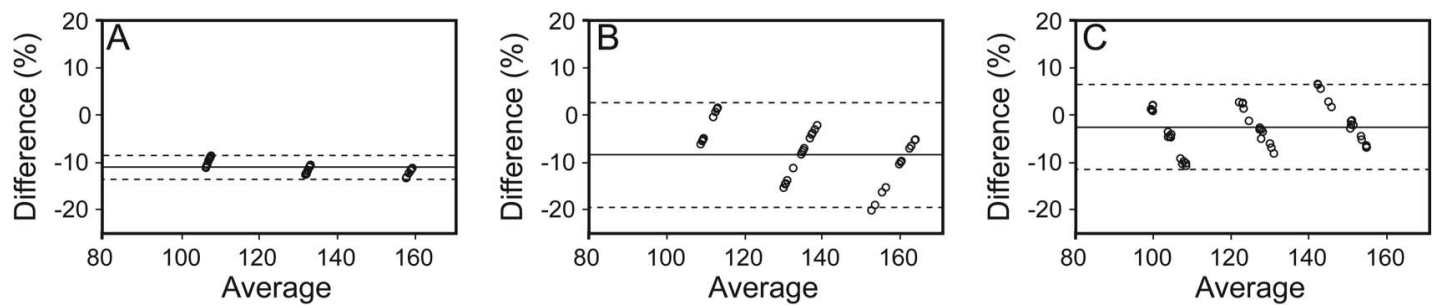

Fig. 3. Bland-Altman plots of carbon dioxide elimination $\left(\dot{\mathrm{V}}_{\mathrm{CO}_{2}}\right)$ result in the pediatric range compared with the simulated values and with each other. MGC Diagnostics CCM Express indirect calorimeter (A) and Philips Healthcare NM3 (B), where difference $(\%)=100 \times$ (measured value - set value)/[(measured value + set value)/2] versus average of the measured value and set value. C: Comparison of MGC with NM3, where difference $(\%)=100 \times(\mathrm{CCM}-\mathrm{NM}) /[(\mathrm{CCM}+\mathrm{NM} 3) / 2]$ versus average.
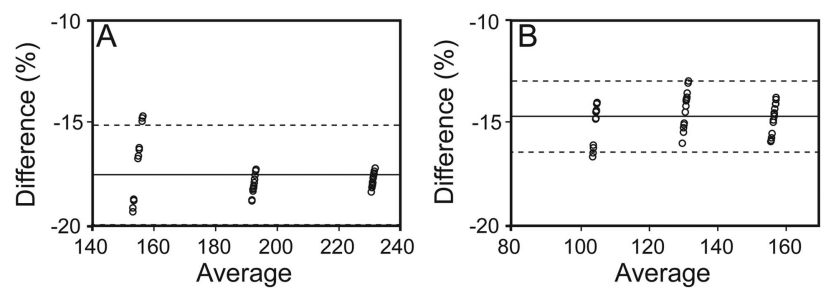

Fig. 4. Bland-Altman plots of oxygen consumption $\left(\dot{\mathrm{V}}_{\mathrm{O}_{2}}\right)$ results as measured using the MGC Diagnostics CCM Express indirect calorimeter in the adult $(\mathrm{A})$ and pediatric $(\mathrm{B})$ range compared with the simulated values. Difference $(\%)=100 \times($ measured value - set value $) /[($ measured value + set value $) / 2]$ versus average of the measured value and set value.

measure gas exchange during noninvasive ventilation. ${ }^{15}$ Subsequently, the model has been modified for simulation of spontaneous breathing simulation as in the present study. Wines et $\mathrm{al}^{16}$ described the application of a similar simulation device to test the accuracy of an indirect calorimeter device over a wide range of gas exchange values. Indirect calorimeter accuracy and agreement have been explored in critically ill adult subjects. ${ }^{17,18}$ Black et al ${ }^{17}$ recently described the agreement of 3 techniques for gas exchange measurement and demonstrated that the bias between devices was acceptable, but the precision was relatively poor. Although the aforementioned studies address important questions for commercially available devices, neither the CCM Express nor the NM3 have been explored sufficiently. There- fore, our present study adds to the literature, and our observations will aid clinicians in determining the correct device for select cohorts.

Currently available gas exchange monitors use different methods for gas sampling and analyses. However, it was not the goal of the present study to specifically compare these methods, because it has been done previously. ${ }^{17,19-21}$ In our current study, the $\dot{\mathrm{V}}_{\mathrm{CO}_{2}}$ measurements between the CCM Express indirect calorimeter and the NM3 volumetric capnography device were in agreement despite technological differences in flow and gas concentration measurement.

Although the values from both devices were within the a priori determined limits of $\pm 20 \%$, it must be noted that the CCM Express underestimated the gas exchange values by an average of $\sim 16 \%$ for $\dot{\mathrm{V}}_{\mathrm{O}_{2}}$. This may result in unintended underprescription of energy, which could be clinically relevant in malnourished children. Table 1 and Figure 4 show this consistent bias. The reasons for this bias are not clear from our experiments. Despite a thorough evaluation for leaks in the experimental setup, a consistent leak during these experiments could result in a consistent bias such as the one described above, and this bias would affect results for all testing conditions with both devices. Future clinical studies must explore this and determine the source of the bias and the need to account for it when interpret the measurements by CCM Express. 
There are important limitations to the present study that must be considered. First, the study was not conducted on human subjects. Rather, a metabolic simulator with precise control of respiratory parameters and gas exchange values was used. The present study attempts to limit the pitfalls of using an in vitro design to simulate not only gas exchange values, but also respiratory parameters that are typically observed in both adult and pediatric patients (including $\mathrm{V}_{\mathrm{T}}$, breathing frequency, inspiratory and expiratory flow patterns, and inspiratory time). Further, the use of an in vitro system has important advantages over clinical testing due to the ability to precisely control respiratory parameters as mentioned above. However, the accuracy of the system components is an important consideration when interpreting the findings. For volume delivery with the ASL 5000, accuracy is $\pm 2.0 \%$, and for gas injection with the mass flow controller, the accuracy is $\pm 0.8 \%$ of the measurement reading; the expected combined maximum error propagation of the accuracy of these components would be $\pm 2.8 \%$. Finally, because both devices yielded measurements below the reference method for both $\dot{\mathrm{V}}_{\mathrm{O}_{2}}$ and $\dot{\mathrm{V}}_{\mathrm{CO}_{2}}$, it is possible that the method of simulation introduced a systematic bias. However, great lengths were taken to ensure that the system was free of leaks, and all equipment was tested before use.

The next steps should include well-controlled clinical studies that discern the agreement between the 2 devices. Methods for transmitting continuous gas exchange monitoring data to electronic medical records would be desirable. The ultimate aim is to use validated gas exchange devices that provide accurate measurements of $\dot{\mathrm{V}}_{\mathrm{O}_{2}}$ and/or $\dot{\mathrm{V}}_{\mathrm{CO}_{2}}$, which can be applied at the bedside for daily titration of nutritional and respiratory therapies.

\section{Conclusions}

Currently available portable gas exchange monitors demonstrated acceptable, albeit variable agreement with simulated $\dot{\mathrm{V}}_{\mathrm{O}_{2}}$ and $\dot{\mathrm{V}}_{\mathrm{CO}_{2}}$ values. The CCM Express and the NM3 measured $\dot{\mathrm{V}}_{\mathrm{CO}_{2}}$ with small mean bias and acceptable limits of agreement in both the pediatric and adult range.

\section{REFERENCES}

1. Mehta NM, Bechard LJ, Dolan M, Ariagno K, Jiang H, Duggan C. Energy imbalance and the risk of overfeeding in critically ill children. Pediatr Crit Care Med 2011;12(4):398-405.

2. Mehta NM, Compher C. A.S.P.E.N. Clinical guidelines: nutrition support of the critically ill child. JPEN J Parenter Enteral Nutr 2009; 33(3):260-276.
3. Walsh BK, Crotwell DN, Restrepo RD. Capnography/capnometry during mechanical ventilation: 2011. Respir Care 2011;56(4):503509.

4. Fraipont V, Preiser JC. Energy estimation and measurement in critically ill patients. JPEN J Parenter Enteral Nutr 2013;37(6):705-713.

5. Framson CM, LeLeiko NS, Dallal GE, Roubenoff R, Snelling LK, Dwyer JT. Energy expenditure in critically ill children. Pediatr Crit Care Med 2007;8(3):264-267.

6. Mtaweh H, Smith R, Kochanek PM, Wisniewski SR, Fabio A, Vavilala MS, et al. Energy expenditure in children after severe traumatic brain injury. Pediatr Crit Care Med 2014;15(3):242-249.

7. Martinez EE, Smallwood CD, Bechard LJ, Graham RJ, Mehta NM. Metabolic assessment and individualized nutrition in children dependent on mechanical ventilation at home. J Pediatr 2015;166(2):350357.

8. Huszczuk A, Whipp BJ, Wasserman K. A respiratory gas exchange simulator for routine calibration in metabolic studies. Eur Respir $\mathbf{J}$ 1990;3(4):465-468.

9. Lindahl SG. Oxygen consumption and carbon dioxide elimination in infants and children during anaesthesia and surgery. Br J Anaesth 1989;62(1):70-76.

10. Lindahl SG, Offord KP, Johannesson GP, Meyer DM, Hatch DJ. Carbon dioxide elimination in anaesthetized children. Can J Anaesth 1989;36(2):113-119.

11. Smallwood CD, Walsh BK, Bechard LJ, Mehta NM. Carbon dioxide elimination and oxygen consumption in mechanically ventilated children. Respir Care 2015;60(5):718-723.

12. Bland JM, Altman DG. Statistical methods for assessing agreement between two methods of clinical measurement. Lancet 1986;1(8476): 307-310.

13. Behrends M, Kernbach M, Bräuer A, Braun U, Peters J, Weyland W. In vitro validation of a metabolic monitor for gas exchange measurements in ventilated neonates. Intensive Care Med 2001;27(1): 228-235.

14. Mehta NM, Smallwood CD, Joosten KF, Hulst JM, Tasker RC, Duggan CP. Accuracy of a simplified equation for energy expenditure based on bedside volumetric carbon dioxide elimination measurement: a two-center study. Clin Nutr 2015;34(1):151-155.

15. Smallwood CD, Mehta NM. Accuracy of gas exchange monitoring during noninvasive ventilation: an in vitro metabolic simulation. JPEN J Parenter Enteral Nutr 2014;38(1):86-91.

16. Wines KN, Rzepecki AK, Andrews AL, Dechert RE. Validation of the $\mathrm{V}_{\max }$ metabolic cart in a simulated pediatric model. JPEN $\mathrm{J}$ Parenter Enteral Nutr 2015;39(3):353-358

17. Black C, Grocott MP, Singer M. Metabolic monitoring in the intensive care unit: a comparison of the Medgraphics Ultima, Deltatrac II, and Douglas bag collection methods Br J Anaesth 2015;114(2):261268.

18. Ashcraft CM, Frankenfield DC. A test of validity of a new opencircuit indirect calorimeter. JPEN J Parenter Enteral Nutr 2015;39(6): 738-742.

19. Smallwood CD, Mehta NM. Gas exchange measurement during pediatric mechanical ventilation: agreement between gas sampling at the airway and the ventilator exhaust. Clin Nutr 2013;32(6):988-992.

20. Siobal MS, Ong H, Valdes J, Tang J. Calculation of physiologic dead space: comparison of ventilator volumetric capnography to measurements by metabolic analyzer and volumetric $\mathrm{CO}_{2}$ monitor. Respir Care 2013;58(7):1143-1151.

21. Jaffe MB, Orr JA. Continuous monitoring of respiratory flow and $\mathrm{CO}_{2}$ :challenges of on-airway measurements. IEEE Eng Med Biol Mag 2010;29(2):44-52. 